\title{
PERCEPÇÃO PARENTAL DAS BARREIRAS PARA O CONTATO DA CRIANÇA COM A NATUREZA
}

\author{
Patrícia Maria Schubert Peres ${ }^{1}$ \\ Maíra Longhnotti Felippe ${ }^{2}$ \\ Ariane Kuhnen ${ }^{3}$
}

\begin{abstract}
Resumo: Esse estudo visou caracterizar o uso de espaços abertos de lazer com natureza por crianças e identificar os recursos materiais e sociais do sistema familiar que são percebidos pelos pais como barreiras ao uso desses locais. Em um parque urbano em Florianópolis 72 pais de crianças de 6 aos 9 anos de idade foram recrutados para participar de um jogo na natureza e responder um questionário auto-aplicado. A maioria dos pais declarou visitar semanalmente com seus filhos espaços abertos de lazer como praias, parques e praças. A principal barreira percebida foi a falta de disponibilidade dos pais para acompanhar os seus filhos a esses lugares. Por outro lado, os pais mostraram-se satisfeitos com a estrutura física dos espaços com natureza e de um modo geral não percebem a distância de lugares com natureza de sua residência como um fator limitante para acessá-los. Tratando-se de um estudo exploratório, sugere-se uma investigação mais aprofundada da organização das atividades familiares como uma condição reguladora das oportunidades de contato da criança com a natureza.
\end{abstract}

Palavras-chave: Criança. Natureza. Família

\section{PARENTAL PERCEPTION OF BARRIERS TOWARDS CHILDREN’S CONTACT WITH NATURE}

\begin{abstract}
This study aimed to characterize the use of children's leisure open space with nature and identify the material and social resources of the family system perceived as barriers of access to these places. In an urban public space at Florianópolis, 72 parents of 6-to-9-years old children were approached to participate in a game in nature and answer a self-applicable questionnaire. The majority of the parents declared to visit weekly leisure open spaces with nature such as beaches, parks and squares. The main barrier perceived was the lack of parents' disponibilility to accompain their children to these places. On the other hand, the parents appeared satisfied with the physical structure of the spaces in nature and, in general, do not perceive the distance from their residences to these areas as limiting factor of accessing them. Since this is an exploratory study, we suggest a deeper investigation of the organization of family activities as a regulatory condition of opportunities for children's contact with nature.
\end{abstract}

Keywords: Children. Nature. Family.

\section{PERCEPCIÓN PARENTAL DE LAS BARRERAS AL CONTACT DEL NIÑO COM LA NATURALEZA}

Resumen: Este estudio tuvo como objetivo caracterizar el uso de espacios abiertos de ocio en la naturaleza por parte de los niños e identificar los recursos materiales y sociales del sistema familiar que los padres perciben como barreras para el uso de estos lugares. En un parque urbano en Florianópolis, 72 padres de niños de 6 a 9 años fueron reclutados para participar en un juego en la naturaleza y responder un cuestionario autoadministrado. La mayoría de los padres informaron visitar espacios abiertos semanales con sus hijos, como playas, parques y plazas. La principal barrera percibida fue la falta de voluntad de los padres para acompañar a sus hijos a estos lugares. Por otro lado, los padres estaban satisfechos con la estructura física de los espacios naturales y, en general, no perciben la distancia de los lugares naturales desde su residencia como un factor limitante para acceder a ellos. Como estudio exploratorio, se sugiere una mayor investigación de la organización de actividades familiares como una condición que regula las oportunidades de contacto de los niños con la naturaleza.

Palabras llave: Niños. Naturaleza. Familia

\footnotetext{
${ }^{1}$ Bióloga e Doutora em Psicologia pelo Programa de Pós-Graduação da Universidade Federal de Santa Catarina.

2 Arquiteta e Urbanista, Doutora em Tecnologia da Arquitetura e Professora Adjunta do Departamento de Arquitetura e Urbanismo e do Programa de Pós-Graduação em Arquitetura e Urbanismo da Universidade Federal de Santa Catarina.

3 Psicóloga, Mestre em Sociologia Política, Doutora em Ciências Humanas, Professora do Departamento de Psicologia e do Programa de Pós-Graduação em Psicologia da Universidade Federal de Santa Catarina.
} 


\section{Introdução}

O contato regular da criança com a natureza traz diversos benefícios ao seu desenvolvimento motor, social, cognitivo e emocional (KELLERT, 2002; WORLD HEALTH ORGANIZATION, 2016). Para usufruir desses benefícios, as crianças necessitam encontrar no ambiente familiar oportunidades de uso de espaços abertos de lazer com natureza como parques, praças, jardins, entre outros (JARVIS; NEWMAN; SWINIARSKI, 2014; SKAR; KROGH, 2009; SKAR; GUNDERSEN; O’BRIEN, 2016; VEITCH; BAGLEY; BALL; SALMON, 2006). As oportunidades de acesso aos locais com natureza pelas crianças são fornecidas pela disponibilidade de certos recursos sociais e materiais no sistema familiar.

A família é considerada um sistema ecológico no campo de estudo da Psicologia do Desenvolvimento Humano. Entende-se por sistema ecológico um ambiente formado por objetos, pessoas e símbolos do contextoque estão em constante inter-relação (BRONFENBRENNER, 2002). A inter-relação desses elementos do ambiente que estruturam o sistema familiar são os propulsores do desenvolvimento humano. Os objetos e as pessoas e os símbolos são também denominados recursos dos contextos de convívio das pessoas e, que pelas suas características, podem alavancar ou retardar o processo de desenvolvimento.

Os recursos podem ser biopsicológicos, materiais e sociais. Os recursos biopsicológicos são capacidades, conhecimentos, habilidades, experiências e inteligência que influenciam o engajamento da pessoa com o ambiente. Os recursos materiais são os elementos físicos do ambiente com os quais a pessoa interage e que sustentam o seu desenvolvimento, por exemplo, local de moradia, espaços de lazer, alimento e educação formal. Os recursos sociais, por sua vez, correspondem às pessoas ou ao contexto social do ambiente com o qual a pessoa se relaciona e que contribuem para o seu desenvolvimento, como o cuidado parental, atividades sociais, amizades, entre outros (BONFENBRENNER, 1993; 1999).

A partir desse entendimento, identifica-se na literatura científica recursos materiais que facilitam o contato da criança com a natureza, como: apresença de natureza nos espaços de convivência da criança (GUNDERSEN, SKAR, O'BRIEN, WOLD, FOLLO, 2016), infraestrutura de recreação e conforto à família em espaços ao ar livre (REFSHAUGE; STIGSDOTTER; PETTERSEN, 2012; VEITCH, 1996; VEITCH et al., 2006), espaços abertos recreativos com natureza nos arredores das residências (COOMBES; JONES; HILLSDON, 2010; FERMINO; REIS; CASSOU, 2012; REFSHAUGE; STIGSDOTTER; PETTERSEN, 2012; O’CONNOR;CERIN; LEE; PARKER; CHEN; HUGES; MENDOZA; BARANOWSKI, 2014) esegurança nos espaços de mobilidade e exploração das crianças (FYHRI; HJORTHOL, 2009; JARVIS; NEWMAN; SWINIARSKI, 2014; PREZZA; ALPARONE; CRISTALLO; 
LUIGI,2005; SKAR; KROGH，2009; TIMPERIO; CRAWFORD; TELFORD; SALMON, 2004).

Dos recursos sociais, destacam-se os fatores parentais que podem atuar como intervenientes da relação da criança com a natureza, são eles: preferência e disponibilidade dos pais para realizar atividades ao ar livre (AARTS;DE VRIES; VAN OERS; SCHUIT,2010; CLEMENTS, 2004; GUNDERSEN et al., 2016; JARVIS; NEWMAN; SWINIARSKI, 2014; LARSON; GREEN; CORDELL, 2011; MCFARLAND;ZAJICEK; WALLCZEK, 2014; SKAR; KARSTEN, 2005; REMMERS; BROEREN; RENDERS; HIRASING; VAN GRIEKEN; RAAT, 2014; SKAR; KROGH, 2009; VEITCH et al., 2006; WITTEN; KEARNS; CARROLL, ASIASIGA, TAVA`E, 2013); condição socioeconômica e educacional dos pais (AARTS et al., 2010; SOORI; BHOPAL, 2002); e experiência dos pais com seus filhos em espaços ao ar livre (REMMERS, et al., 2014; SKAR; KROGH, 2009) .

Quando os recursos materiais e sociais do sistema familiar estão ausentes ou fragilizados, estes podem ser considerados barreiras ao contato da criança com a natureza. A percepção parental pode fornecer informações sobre essas barreiras, devido as funções que os pais exercem na família ao participar das escolhas dos lugares as serem visitados pelas crianças, permitir ou restringir o uso de certos locais e/ou, ainda, monitorar e organizaras atividades no ambiente familiar (VEITCH et al., 2006; WELLS, 2000). Ante ao apresentado, o presente estudo visou caracterizar o uso de espaços abertos de lazer com natureza por criança de 6 a 9 anos de idade e identificar as barreiras percebidas pelos pais ao uso desses locais no sistema familiar.

\section{Método}

Contexto de estudo

A cidade de Florianópolis (SC) possui uma área territorial de $675.409 \mathrm{Km}^{2}$, caracterizada por uma parte insular e continental. O número de habitantes é de 421.240 , tendo em torno de 23.979 crianças com idade de 5 a 9 anos, que é a faixa etária deste estudo (IBGE, 2010). Pela sua localidade litorânea, as praias são os principais atrativos de lazer, principalmente, no verão. Entretanto, as áreas verdes de lazer como praças públicas e parques urbanos e infantis são tradicionalmente ocupados pelas famílias durante todo o ano e são considerados escassos, frente ao tamanho populacional da cidade (PREFEITURA DE FLORIANÓPOLIS, 2015).

Dado o crescimento populacional da cidade, a ocupação urbana tem se dado, principalmente, pelo aumento do número de edifícios verticalizados e da ampliação do sistema viário. Em consequência, a urbanização tem sido diagnosticada por uma estrutura precária de calçadas e tráfego intenso de automóveis, que torna o espaço urbano não convidativo à mobilidade de pedestres (GOVERNO DE SANTA CATARINA, 2015). Além disso, os 
interesses imobiliários que levam a intensificação da ocupação da região central de Florianópolis contribui para a um processo de favelização atrelado a riscos ambientais e carência de serviços públicos e de infraestrutura no âmbito da educação, saúde, segurança e lazer.

Como parte da infraestrutura da cidade estão os espaços abertos com natureza. Devido aos aterramentos e construções viárias e prediais da região central de Florianópolis, as áreas naturais formadas por ecossistemas como manguezais, praias, restingas e dunas sofreram uma diminuição drástica. Parte das paisagens naturais estão resguardadas em áreas verdes de lazer como nos parques urbanos e nas áreas de preservação. Dada a importância dos parques urbanos como espaços de preservação de ecossistemas naturais, a pesquisa foi realizada em um parque público localizado na região central de Florianópolis.

O parque é considerado uma área verde de lazer de 22 hectares e que conjuga uma vegetação de Mata Atlântica a uma estrutura recreativa constituída por trilhas, parque infantil, viveiro, quiosques, academia de ginástica ao ar livre, quadras de tênis e vôlei de praia, lagos com jacarés-de-papo-amarelo e cágados. No local, são oferecidos aos visitantes programas regulares de práticas de atividade física como Yoga e Tai Chi Chuan, além de eventos culturais e atividades de educação ambiental. O Parque está aberto para visitações das $8 \mathrm{~h}$ às $18 \mathrm{~h}$, durante todos os dias da semana e, inclusive, nos feriados.

\section{Participantes e procedimento}

Fizeram parte da pesquisa 72 pais com filhos de 6 aos 9 anos de idade. Dos pais participantes da pesquisa, $36(50 \%)$ eram do sexo feminino. A média de idade foi de 38 anos e 2 meses ( $D P=7$ anos e 4 meses), sendo a idade mínima de 27 anos e a máxima de 54 anos. A maioria dos respondentes declarou possuir ensino superior completo (50) e trabalhar como servidor público (29), empregado de empresa privada (16) e profissional autônomo. Ao tempo da participação, a maioria dos respondentes residia na cidade de Florianópolis $(n=59)$, habitava em apartamentos $(n=29)$ e recebia renda mensal acima de $\mathrm{R} \$ 3.621,00(50)$. A Tabela 1 apresenta mais informações sobre as características sociodemográficas dos participantes.

Dentre as 72 crianças abordadas na pesquisa, 51 eram do sexo feminino. A média de idade das crianças foi de 7 anos e 3 meses ( $D P=1$ ano e 2 meses), sendo a idade mínima de 6 anos e a máxima de 9 anos. Cinquenta e seis crianças eram o primeiro filho do cuidador participante; 10, segundo filho; 1, terceiro filho; e 1, quarto filho. Quatro pais não informaram a posição do filho na família.

Os pais, acompanhados de seus filhos (as), foram recrutados através de um convite para participarem de um jogo de caça ao tesouro na paisagem do parque público. O jogo constituiu a primeira fase pesquisa e era destinado a crianças na faixa de idade dos 6 aos 9 anos. Após o jogo, 
o responsável legal da criança era então convidado para responder ao questionário auto aplicado, perante a apresentação dos procedimentos éticos do Comitê de Ética em Pesquisa com Seres Humanos.

Tabela 1- Dados sociodemográficos dos pais participantes do estudo $(\mathrm{N}=72)$.

\begin{tabular}{|c|c|c|}
\hline Variável & Valores & $\mathbf{N}$ \\
\hline \multirow[t]{7}{*}{ Local de moradia } & Fora de Florianópolis & 11 \\
\hline & Região Central de Florianópolis & 30 \\
\hline & Região Leste de Florianópolis & 3 \\
\hline & Região Norte de Florianópolis & 9 \\
\hline & Região Sul de Florianópolis & 6 \\
\hline & Região Continental de Florianópolis & 11 \\
\hline & Não responderam & 2 \\
\hline \multirow[t]{3}{*}{ Tipo de moradia } & Casa & 29 \\
\hline & Apartamento & 40 \\
\hline & Não responderam & 3 \\
\hline \multirow[t]{4}{*}{ Estado civil } & Casado(a) & 42 \\
\hline & União estável & 15 \\
\hline & Separado(a), Divorciado(a) & 6 \\
\hline & Solteiro(a) & 9 \\
\hline \multirow[t]{5}{*}{ Número de filhos } & Um filho & 36 \\
\hline & Dois filhos & 26 \\
\hline & Três filhos & 5 \\
\hline & Cinco filhos & 1 \\
\hline & Não responderam & 4 \\
\hline \multirow[t]{6}{*}{ Escolaridade } & Ensino superior completo & 50 \\
\hline & Ensino superior incompleto & 7 \\
\hline & Ensino médio completo & 7 \\
\hline & Ensino médio incompleto & 3 \\
\hline & Ensino fundamental completo & 4 \\
\hline & Ensino fundamental incompleto & 1 \\
\hline \multirow[t]{8}{*}{ Ocupação } & Servidor público & 29 \\
\hline & Estudante & 4 \\
\hline & Dona de casa & 2 \\
\hline & Profissional autônomo & 11 \\
\hline & Empresário/comerciante & 6 \\
\hline & Empregado de empresa privada & 16 \\
\hline & Aposentado & 1 \\
\hline & Outro & 3 \\
\hline \multirow[t]{7}{*}{ Faixa de renda } & Acima de $\mathrm{R} \$ 7.241,00$ & 30 \\
\hline & De $\mathrm{R} \$ 6.517,00$ até $\mathrm{R} \$ 7.241,99$ & 6 \\
\hline & De $\mathrm{R} \$ 5.069,00$ até $\mathrm{R} \$ 6.516,99$ & 6 \\
\hline & De R \$ 3.621,00 até $\mathrm{R} \$ 5.068,99$ & 8 \\
\hline & De $\mathrm{R} \$ 1.449,00$ até $\mathrm{R} \$ 3.620,99$ & 17 \\
\hline & De $\mathrm{R} \$ 725,00$ até $\mathrm{R} \$ 1448,99$ & 4 \\
\hline & Até R\$ 724,99 & 1 \\
\hline
\end{tabular}

Fonte: Questionários. Dados organizados pelas autoras

\section{Instrumentos}

O questionário auto aplicado constou de 18 questões do tipo fechadas e agrupadas em quatro temáticas. A primeira temática correspondeu a informações sociodemográficas dos pais. A segunda temática correspondeu a informações de descrição do uso de espaços abertos de lazer com natureza pelas crianças, incluindo opções de espaços abertos de lazer com natureza que os 
pais consideram serem mais visitados pelos seus filhos e a frequência de uso desses espaços.

A terceira temática correspondeu aos recursos materiais e sociais disponíveis do sistema familiar que poderiam ser identificados pelos pais como barreiras ao uso dos espaços abertos de lazer com naturezapor crianças. Os itens foram apresentados como frases que justificavam a afirmativa "Meu filho(a) não visita mais espaços verdes de lazer...", para as quais o respondente assinalava a opção que melhor correspondia a sua percepção em relação a cada justificativa: se discordava muito; discordava; não concordava nem discordava; concordava; concordava muito. As sentenças foram construídas a partir de referenciais teóricos encontrados na literatura e explicitados no Quadro 1.

Quadro 1- Barreiras que impedem o uso de espaços abertos identificados na literatura científica.

\section{Frases Barreiras identificadas na literatura}

Porque meu filho Preferência da criança por outras atividades de lazer como ler, escutar prefere outras música, assistir TV/DVDs, jogar vídeo games, utilizar a internet e atividades de lazer. realizar atividades esportivas em espaços fechados são consideradas atividades favorecidas pelo contexto atual urbano e que competem com atividades livres em espaços abertos (LARSON; GREEN;CORDELL; 2011; CLEMENTS, 2004).

Porque eu prefiro A indisponibilidade dos pais é uma condição que limita o uso dos outras atividades de lazer. espaços abertos devido à necessidade do acompanhamento de adultos em atividades organizadas para as crianças na natureza (GUNDERSEN Porque nem sempre et al., 2016; LARSON; GREEN; CORDELL, 2011; MCFARLAND et estou disponível al., 2014). para acompanhá-lo. Por falta de tempo do filho (a)

Atividades extracurriculares e atividades de lazer organizadas concorrem com atividades livres em espaços abertos (CLEMENTS, 2004).

Porque tive Os pais se sentem inseguros quanto à mobilidade autônoma de crianças experiências em espaços abertos devido ao tráfego intenso e a presença de estranhos desagradáveis com (PREZZA et al., 2005;TIMPERIO et al., 2004;VALENTINE; meu filho nos MCKENDRICK, 1997). espaços de lazer com natureza Porque os espaços de lazer com natureza não têm A má conservação dos espaços abertos de lazer constitui uma razão pela qual os pais não permitem o uso desses locais (VEITCH et al.,2006). boa estrutura física.

Fonte: Questionários. Dados organizados pelas autoras

Análises de dados

Variáveis nominais foram descritas em termos de frequência e variáveis numéricas foram 
descritas por meio de medidas de tendência central e dispersão. Em caso de distribuições não normais ou para dados oriundos de escalas numéricas ordinais (Likert) foram utilizadas a mediana como medida de tendência central, a amplitude como medida de dispersão e testes não paramétricos para análises relacionais. Em caso de distribuições normais ou para dados oriundos de escalas numéricas intervalares ou de razão, foram utilizadas a média como medida de tendência central, o desvio padrão como medida de dispersão e testes paramétricos para análises relacionais.

\section{Resultados}

Dentre os lugares mais visitados, considerando-se a totalidade dos registros obtidos $(N=$ $216)$, destacaram-se a praia $(29,63 \%)$, o parque urbano $(18,51 \%)$, o parque ou reserva florestal $(13,43 \%)$, o pátio da escola $(11,11 \%)$ e a praça $(11,11 \%)$. Já o quintal de casa, a área verde do condomínio, o sítio, a duna e o mangue foram os menos citados, sendo juntos responsáveis por $20,82 \%$ das marcações. Os ambientes com maior número de registros foram também aqueles mais visitados em primeiro lugar, tendo a praia obtido o maior número de registros nas três posições de ordem de visitação (ver Tabela 2).

$\mathrm{Na}$ pergunta sobre os locais mais visitados pelas crianças em primeiro, segundo e terceiro lugar, verificou-se que a maior parte das citações $(52,78 \%)$ nas três ordens de visitação corresponde a locais que estão a mais de $2 \mathrm{~km}$ de distância da residência. Embora a maior parte dos locais mais visitados esteja na faixa de maior distância, nota-se que um segundo grupo de lugares, correspondente a 23,61\% das citações, são aqueles mais próximos da residência (menos de $500 \mathrm{~m})$. As demais indicações $(23,61 \%)$ correspondem a lugares em uma faixa intermediária de distância em relação à habitação (de $500 \mathrm{~m}$ a $1 \mathrm{~km}$ e de 1 a $2 \mathrm{~km}$ ). Mais detalhes dos dados podem ser vistos na Tabela 2. O teste Qui-quadrado $\left(\chi^{2}\right)$, utilizado para verificar a existência de uma associação entre a ordem de visitação e a distância dos lugares em relação à residência, não indicou evidência de relação entre as duas variáveis $\left(\chi 2=0,876, g l=6, p=0,99 ; \mathrm{V}_{\text {Cramer }}=0,045 ; N\right.$ $=216)$. 
Tabela 2 - Distribuição do número de indicações dos espaços abertos de lazer com natureza nas ordens de visitação

\begin{tabular}{lccccc}
\hline & \multicolumn{7}{c}{ Ordem de visitação } & & \\
Espaços abertos com natureza & $\begin{array}{c}\text { Primeiro } \\
\text { lugar }\end{array}$ & $\begin{array}{c}\text { Segundo } \\
\text { lugar }\end{array}$ & $\begin{array}{c}\text { Terceiro } \\
\text { lugar }\end{array}$ & $\mathrm{n}$ & $\%$ \\
Praia & 27 & 19 & 18 & 64 & 29,63 \\
Mangue & 0 & 1 & 0 & 1 & 0,46 \\
Duna & 0 & 2 & 3 & 5 & 2,31 \\
Parque/Reserva Florestal & 8 & 10 & 11 & 29 & 13,43 \\
Parque urbano & 10 & 13 & 7 & 40 & 18,52 \\
Praça & 8 & 7 & 9 & 24 & 11,11 \\
Sítio/Fazenda & 0 & 3 & 4 & 7 & 3,24 \\
Pátio da escola & 10 & 6 & 8 & 24 & 11,11 \\
Área verde do condomínio & 3 & 4 & 7 & 14 & 6,48 \\
Quintal de casa, de familiares ou de & 6 & 7 & 5 & 18 & 8,33 \\
amigos & & & & & \\
Total (N) & $\mathbf{7 2}$ & $\mathbf{7 2}$ & $\mathbf{7 2}$ & $\mathbf{2 1 6}$ & $\mathbf{1 0 0 \%}$ \\
\hline Fonte: Questiórion
\end{tabular}

Fonte: Questionários. Dados organizados pelas autoras

Quando indagados a respeito da frequência com que o filho(a) costuma visitar espaços abertos de lazer com natureza, a maioria dos pais indicou ser esta semanal $(n=42)$, seguida da mensal $(n=21)$, diária $(n=6)$ e semestral $(n=3)$. De fato, para o último mês, 62 pais informaram que o filho frequentou espaços abertos de lazer com natureza mais que três vezes ( $n$ =36) ou de duas a três vezes $(n=26)$. Apenas dez pais relataram frequência de até uma visita para o último mês. A maior parte dos 71 respondentes declarou estar presente nessas visitas sempre $(n=36)$ e quase sempre $(n=25)$, sendo que 9 acompanham o filho(a) às vezes e apenas 1 , quase nunca.

$\mathrm{Na}$ questão onde pais foram convidados a avaliar as barreiras de acessibilidade do filho(a) aos espaços abertos de lazer, houve uma tendência a discordar com as barreiras apresentadas, exceto pelo item que trata da disponibilidade dos pais para acompanhar as crianças (Tabela 3 ). Nesse sentido, destaca-se também o item "Porque os espaços com natureza são distantes de casa”, que pode ser considerado o segundo fator mais percebido como empecilho. Observa-se em cada linha da Tabela 3 que a maior parte das respostas se situa na zona de discordância, o que equivale a dizer que o conteúdo das frases não é visto como empecilho à visitação. $\mathrm{O}$ item "Porque tive experiências desagradáveis com meu filho nos espaços de lazer com natureza"foi aquele menos percebido como barreira, seguido dos itens "Porque meu filho prefere outras 
atividades" e "Porque os espaços de lazer com natureza não têm boa estrutura física". O teste de Kruskal-Wallis não encontrou uma possível relação entre as barreiras e a frequência de visitação geral e mensal.

Tabela 3 - Número de indicações das barreiras de acessibilidade aos espaços abertos de lazer com natureza

Barreiras de acessibilidade

Meu filho não visita mais espaços mais vezes espaços de lazer com natureza...

Porque meu filho prefere outras atividades.

Porque eu prefiro outras atividades.

Porque nem sempre estou disponível para acompanhá-lo.

Por falta de tempo do filho Porque os espaços com natureza são distantes de casa.

Porque tive experiências desagradáveis com meu filho nos espaços de lazer com natureza.

Porque os espaços de lazer com natureza não têm boa estrutura física.
Escala de concordância (n)

Não

\begin{tabular}{|c|c|c|c|}
\hline $\begin{array}{l}\text { Discordo } \\
\text { muito }\end{array}$ & Discordo & $\begin{array}{l}\text { concordo } \\
\text { nem }\end{array}$ & Concordo \\
\hline
\end{tabular}

19

15

38

9

6

0

0

10

18

9

29

6

17

39

1

10

5

14

27

7

20

4

54

17

1

0

0

21

33
11

Fonte: Questionários. Dados organizados pelas autoras

\section{Discussão}

Os resultados caracterizamo uso semanal dos espaços abertos de lazer com natureza distantes da residência familiar como a praia e os parques urbanos e florestais e a praça. Sessenta e dois pais informaram que o(a) filho(a) frequenta espaços abertos de lazer com natureza mais que três vezes ou de duas a três vezes por mês e, 42 pais informaram uma frequência semanal. Esses resultados indicam uma regularidade de contato semanal da criança com a natureza. De acordo com a Organização Mundial de Saúde (WHO, 2016), atividades ao ar livre deveriam ser realizadas diariamente, por pelo menos uma hora, como uma forma de criar oportunidades para a prática de atividade física.

No que diz respeito a visita de espaços abertos de lazer com natureza mais distantes das residências, esperava-se que os locais mais próximos fossem os mais frequentados pelas crianças. Alguns estudos mostram resultados que corroboram com a hipótese de que a frequência 
de visitação de espaços ao ar livre recreativos está negativamente relacionada à distância das residências (COOMBES et al., 2010; FERMINOet al., 2012; O’CONNOR et al., 2014). No presente estudo, os pais relataram visitar com suas crianças espaços abertos de lazer com natureza localizado mais que $2 \mathrm{~km}$ de suas residências e não identificaram a distância uma barreira ao uso de espaços com natureza.

A preferência por visitar locais distantes pode ser um indicador de um estilo de vida que inclui o uso frequente do automóvel. Embora não tenha sido investigado o uso de transporte entre os participantes da pesquisa, o automóvel é o principal meio de transporte utilizado em grandes centros urbanos brasileiros como Florianópolis (GOVERNO DE SANTA CATARINA, 2015). Em Refshauge et al. (2012), por exemplo, compararam o uso de espaços abertos com natureza por famílias Dinamarquesas e Estadunidenses e encontrou que pais Estadunidenses dirigem longas distâncias para levar seus filhos em parques infantis com natureza, mesmo que esses locais estejam disponíveis nos arredores de suas residências; ao contrário, os pais Dinamarqueses utilizam os parques infantis com natureza acessíveis a pé ou de bicicleta. Os pesquisadores explicam essa diferença pelo estilo de vida adotada pela família, tendo em vista que as condições socioeconômicas e as condições de transporte são similares em ambos países.

Os pais indicaram as praias como os locais mais visitados, negligenciando os outros espaços. Florianópolis é uma cidade conhecida pela diversidade de suas paisagens naturais como praias, manguezais, restinga e matas que circundam e integram as áreas urbanizadas. Tratando-se de um balneário, é esperado que as praias sejam os espaços mais frequentados pelas famílias e que áreas abertas de residências, condomínio, escolas e praças passem despercebidas como lugares que também podem oferecer às crianças contato com natureza. Por uma preferência dos pais por espaços com paisagens mais preservadas, nutrida por uma cultura que valoriza a visitação de espaços mais distantes, locais nos arredores urbanos passam despercebidos e desvalorizados como áreas com potencial recreativo e disponível no dia a dia da criança.

A visitação de espaços abertos de lazer com natureza pela criança com o acompanhamento dos pais torna a disponibilidade parental um recurso social importante para o contato da criança com a natureza. De fato, 71 dos 72 pais relataram acompanhar seus filhos aos espaços abertos de lazer com natureza. O acompanhamento parental é uma condição cada vez mais observada nas atividades informais das crianças devido, principalmente, a uma percepção de risco dos pais em relação a falta de segurança no tráfego urbano e a necessidade do uso do automóvel (FYHRI, HJORTHOL, 2009; SOORI; BHOPAL, 2002).

A cidade de Florianópolis, como muitas cidades brasileiras, apresenta dificuldades com relação a mobilidade segura de pedestres. De acordo com o Plano de Mobilidade Urbana deFlorianópolis, a estrutura física das ruas como calçadas e alto tráfego de automóveis privados 
não favorecem a mobilidade segura e rápida de pedestres (GOVERNO DE SANTA CATARINA, 2015). Esta condição de insegurança gera, possivelmente, nos pais a necessidade de transportar e acompanhar seus filhos até os espaços abertos de lazer.

A dependência do acompanhamento parental torna a disponibilidade parental uma das principais barreiras ao uso de espaços abertos com natureza pela criança. Estudos têm encontrado uma relação significativa do tempo disponível dos adultos com a frequência de uso de espaços abertos de lazer com natureza por crianças (GUNDERSENet al., 2016; LARSONet al., 2011). No presente estudo, aproximadamente metade dos pais justificaram o uso não frequente dos espaços abertos de lazer com natureza pela indisponibilidade para acompanhar os seus filhos até esses locais.

O perfil sociodemográfico dos pais aponta para uma relação entre a disponibilidade parental e o número de horas no trabalho. A maioria dos pais declarou-se com ensino superior completo e exercendo ocupações profissionais de servidor público e empregado de empresa privada. Estas são categorias de emprego que se caracterizam pelo cumprimento de um regime de horas diárias de trabalho de 6 a 8 horas, o que não permite tempo livre suficiente para realizar atividades de lazer com os filhos durante a semana. Estudos realizados em países como Estados Unidos e Noruega, por exemplo, encontraram uma relação positiva entre disponibilidade parental nos finais de semana com a quantidade de tempo que crianças despendem nesses lugares (GUNDERSEN et al., 2016; LARSON et al.,2011).

$\mathrm{O}$ uso dos espaços abertos de lazer com natureza depende também da disponibilidade e interesse da criança por esses locais. Mesmo que as crianças tenham outras atividades de lazerpreferidas e um cronograma semanal de várias atividades formais, amaioria dos pais não identificou a falta de tempo das crianças e apreferência por outras atividades como barreiras para o uso maisfrequente dos espaços abertos de lazer com natureza. Uma explicação pode estar na satisfação dos pais em relação aos tipos e a quantidade detempo dedicado às outras atividades frente ao uso que elas fazem dos espaços abertos de lazer com natureza.

Uma vez que os pais encontram-se disponíveis para acompanhar os seus filhos aos espaços abertos de lazer com natureza, a satisfaçãopara com a estrutura física desses locaisé um motivador importante para o uso e permanência das crianças na natureza. De um modo geral, os pais mostraram-se satisfeitos com o ambiente físico dos locais comumente visitados por eles. A satisfação dos pais com a estrutura do local está normalmente relacionada à menor percepção de risco e a presença de infraestrutura que estimule a permanência da família no local, como a existência de banheiros e áreas sombreadas (REFSHAUGEet al., 2012; VEITCHet al., 2006).

\section{Considerações Finais}


Este estudo apresenta um perfil de famílias que visita semanalmente os espaços abertos de lazer com natureza. Os pais levam seus filhos preferencialmente aos espaços mais distantes de suas residências e onde a natureza é mais preservada como em praias e parques urbanos e florestais. O ecossistema de Mata Atlântica litorâneo que envolve Florianópolis cria oportunidades de atividades às famílias em meio a natureza. A visita desses locais torna-se, portanto, parte da cultura familiar e que, portanto, são potencialmente espaços que crianças brincam, descansam e se socializam.

A disponibilidade parental se destacou como a principal barreira ao uso de espaços abertos de lazer com natureza pelas crianças. Dado que os pais acompanham frequentemente os seus filhos aos espaços abertos de lazer, a disponibilidade parental mostra-se como um importante recurso social que intervém no contato da criança com a natureza. Sugere-se que a disponibilidade dos pais e da criança possa ser aprofundada em estudos qualitativos com o objetivo de compreender a organização das atividades do sistema familiar que influenciam a frequência de uso de espaços abertos de lazer com natureza pela família.

Os pais, como recurso social que provê o acesso de crianças à natureza, precisam estar disponíveis e incentivados a levarem seus filhos aos espaços ao ar livre. O incentivo pode se dar pela oferta de mais espaços abertos de lazer nos bairros e uma estrutura de segurança ao contexto urbano de modo a favorecer o contato cotidiano da criança com a natureza e a mobilidade segura para esses espaços. Além disso, é preciso questionar o estilo de vida apoiado por um sistema econômico e sociocultural que indisponibiliza os pais para proporcionarem atividades de lazer em meio à natureza no cotidiano familiar.

\section{Referências}

AARTS, Marie-Jeanne.; DE VRIES, Sanne-I de; VAN OERS, Hans. AM.; SCHUIT, Albertine. J. Outdoor play among children in relation to neighborhood characteristics: a cross sectional neighborhood observation study. International Journal of Behavioral Nutrition and Physical Activity, v.9, n.98, p. 3-11, 2012. Disponível em:https://doi.org/10.1186/1479-5868-9-98 Acesso em:22 ago. 2019.

BRONFENBRENNER, Urie. The ecology of cognitive development: research models and fugitive findings. In: WOZNIAK, Robert H.\& FISHER, Kurt W. (Ed.). Development in context: acting and thinking in specific environments. Hillsdale-NJ: Erlbaum, 1993. p. 3-44.

BRONFENBRENNER, Urie. A ecologia do desenvolvimento humano: experimentos naturais e planejados. Porto Alegre: Artes Médicas, 1996.

BRONFENBRENNER, Urie.Environments in development perspective: theoretical and operational models. In: Friedman, Sarah. L.\& Wachs, Theodore. D. (ed.). Measuring environment across the life span: emerging methods and concepts. Washington: American Psychological Association, 1999. p. 3-28. 
CLEMENTS, Rhonda. An investigation of the status of outdoor play. Contemporary Issues Early Childhood, v.5, p. 68-80, 2004. Disponível em: https://doi.org/10.2304/ciec.2004.5.1.10. Acesso em: 22 ago. 2019.

COOMBES Emma; JONES, Andrew. P.; HILLSDON, Melvyn. The relationship of physical activity and overweight to objectively measured green space accessibility and use. Social Science \& Medicine. V. 70, p. 816-822, 2010. Disponível em: https://www.ncbi.nlm.nih.gov/pmc/articles/PMC3759315/. Acesso em: 24 abr. 2019.

FYHRI, Aslak.; HJORTHOL, Randi. Children's independent mobility to school, friends and leisure activities. Journal of Transport Geography, v. 17, n.5, p. 377-384, 2009. Disponível em: https://doi.org/10.1016/j.jtrangeo.2008.10.010. Acesso em: 22 ago. 2019.

GOVERNO DE SANTA CATARINA. Secretaria de Estado do Planejamento. Plano de Mobilidade Urbana Sustentável - PLAMUS. Florianópolis, 2015. Disponível em http://www.spg.sc.gov.br/visualizar-biblioteca/acoes/regiao-metropolitana/1085--318/file.

Acesso em: 24 abr. 2019.

FERMINO, Rogério Cesar; REIS, Rodrigo Siqueira; CASSOU, Ana Carina. Fatores individuais e ambientais associados ao uso de parques e praças por adultos de Curitiba-PR, Brasil. Revista Brasileira Cineantropom Desemepenho Humano, v. 14, n. 4, p. 377-389, 2012. Disponível em: http://www.scielo.br/pdf/rbcdh/v14n4/02.pdf. Acesso em: 24 abr. 2019.

GUNDERSEN, Vegard.; SKAR, Margrete; O'BRIEN, Liz; WOLD, Line Camila.; FOLLO, Gro Irene. Children and nearby nature: a nationwide parental survey from Norway. Urban Forestry and Urban Greening, v. 17, p. 116-125, 2016.Disponível em: https://doi.org/10.1016/j.ufug.2016.04.002. Acesso em: 24 abr. 2019.

JARVIS, Pam.; NEWMAN, Stephen.; SWINIARSKI, Louise. On "becoming social": the importance of collaborative free play in childhood. International Journal of Play, v.3, p.53-68, 2014. Disponível em: https://doi.org/10.1080/21594937.2013.863440. Acesso em: 24 abr. 2019.

KARSTEN, Lia. It all used to be better? Different generations on continuity and change in urban children's daily use of space. Children's Geographies, v. 3, p. 275-290, 2005. Disponível em: https://doi.org/10.1080/14733280500352912. Acesso em: 24 abr. 2019.

KELLERT, Stephen. R. Experiencing nature: affective, cognitive, and evaluative development in children. In: KAHN, Peter. H. Jr; KELLERT, Stephen. R. (ed.). Children and Nature: Psychological, Sociocultural, and Evolutionary Investigations.Cambridge: The MIT Press, 2002. p. 117-151.

IBGE - Instituto Brasileiro de Geografia e Estatística. Portal IBGE. 2010. Disponível em: https://www.ibge.gov.br/. Acesso em: 23 de janeiro de 2018.

LARSON, Lincoln. R.; WHITING, Jason. W.; GREEN, Gary. T. Young people's outdoor recreation and state park use: perceived benefits from the parent/guardian perspective. Children, Youth and Environments, v. 23, n.3, p. 89-118, 2013.Disponível em: https://www.jstor.org/stable/10.7721/chilyoutenvi.23.3.0089. Acesso em: 24 abr. 2019.

MCFARLAND, Amy L.; ZAJICEK, Jayne. M.; WALLCZEK, Tina.M. The relationship between parental attitudes toward nature and the amount of time children spend in outdoor recreation. Journal of Liesure Research, v. 46, n. 5, p. 525-539, 2014. Disponível em: https://doi.org/10.1080/00222216.2014.11950341. Acesso em: 24 abr. 2019.

O’CONNOR, Teresia. M.;CERIN, Ester;LEE, Rebecca. E.;PARKER, Nathan;CHEN, TzuAn;HUGES, Sheryl. O.;MENDOZA, Jason. A.;BARANOWSKI, Tom. Environmental and cultural correlates of physical activity parenting practices among Latino parents with preschoolaged children: niños activos. Public Health, v. 14, p. 2-9, 2014. Disponível em: https://www.ncbi.nlm.nih.gov/pmc/articles/PMC4226995/. Acesso em: 24 abr. 2019. 
PREFEITURA DE FLORIANÓPOLIS. Relatório final: estudo 3 Crescimento Urbano. Florianópolis. $2015 . \quad$ Disponível em: http://www.pmf.sc.gov.br/arquivos/arquivos/pdf/27_08_2015_9.30.19.2d57c5303b800097ab787 96419b761af.pdf. Acesso em: 23 de janeiro de 2018.

PREZZA, Miretta; ALPARONE, Francesca Romana; CRISTALLO, Carmela; LUIGI, Secchiano. Parental perception of social risky and of positive potentiality of outdoor autonomy for children: the development of two instruments. Journal of environmental Psychology, v. 25, p. 437-453, 2005.Disponível em: https://doi.org/10.1016/j.jenvp.2005.12.002. Acesso em: 24 abr. 2019.

REFSHAUGE, Anne. Dahl.; STIGSDOTTER, Ulrika. K.; PETERSEN, Lise Spetch. Play and behavior characteristics in relation to the design of four danish public playgrounds. Children, Youth and Environments, v. 23, n.2, p. 22-48, 2012. Disponível em:http://www.jstor.org/stable/10.7721/chilyoutenvi.23.2.0022. Acesso em: 24 abr. 2019.

REMMERS, Teun.; BROEREN, Suzanne. M.; RENDERS, Carry. M.; HIRASING, Remy. Amy; VAN GRIEKEN, A.; RAAT, Hein. A longitudinal study of children's outside play using family environment and perceived physical environment as predictors. International Journal of Behavioral Nutrition and Physical Activity, v. 11, n.1, p. 1-9, 2014. Disponível em: https://ijbnpa.biomedcentral.com/articles/10.1186/1479-5868-11-76. Acesso em: 23 jan. 2018.

SKAR, Margrete.; GUNDERSEN, Vegard.; O’BRIEN, Liz. How to engage children with nature: why not just let them play? Children's Geographies, v. 14, n.5, p. 527-540, 2016. Disponível em: https://doi.org/10.1080/14733285.2015.1136734. Acesso em: 23 jan. 2018.

SKAR, Margrete.; KROGH, Erling. Changes in children's nature-based experiences near home: from spontaneous play to adult-controlled, planned and organized activities. Children's Geographies,v.7, p.339-354, 2009. Disponível em: https://doi.org/10.1080/14733280903024506. Acesso em: 23 jan. 2018.

SOORI, Hamid; BHOPAL, Raj S. Parental permission for children's independent outdoor activity. European Journal of Public Health, v. 12, p. 104-109, 2002. Disponível em: https://doi.org/10.1093/eurpub/12.2.104. Acesso em: 23 de janeiro de 2018.

TIMPERIO, Anna; CRAWFORD, David Andrew.; TELFORD, A.; SALMON, Jo. Perceptions about the local neighborhood and walking and cycling among children. Preventive Medicine, v. 38, n. 1, p. 39-47, 2004. Disponível em: https://doi.org/10.1016/j.ypmed.2003.09.026. Acesso em: 23 jan. 2018.

VALENTINE, Gill.; MCKENDRICK, John. Children's outdoor play: exploring parental concerns about children's safety and the changing nature of childhood. Geoforum, v. 28, n. 2. P. 219-235, 1997. Disponível em: https://doi.org/10.1016/S0016-7185(97)00010-9. Acesso em: 25 abr. 2019.

VEITCH, Jenny; BAGLEY, Sarah; BALL, Kylie; SALMON, Jo. Where do children usually play? A qualitative study of parents' perceptions of influences on children's active free-play. Health \& Place, v. 12, n.4, p. 383-393, 2006.Disponível em: https://doi.org/10.1016/j.healthplace.2005.02.009. Acesso em: 23 jan. 2018.

WELLS, Nancy.M. At home with nature: effects of "greenness" on children's cognitive functioning. Environment and Behavior, v. 32, n.6, p. 775-795, 2000. Disponível em: https://doi.org/10.1177/00139160021972793. Acesso em: 26abr. 2019.

WITTEN, Karen.; KEARNS, Robin.; CARROLL, Penelope; ASIASIGA, Lanuola; TAVA'E, Nicola. New Zealand parents' understandings of the inter- generational decline in children's independent outdoor play and active travel. Children's Geographies, v. 11, n.2, p. 215-229, 2013. Disponível em: https://doi.org/10.1080/14733285.2013.779839. Acesso em: 26 abr. 2019. 
WORLD HEALTH ORGANIZATION. Urban green spaces and health: a review of evidence. Copenhagen, 2016. em: http://www.euro.who.int/_data/assets/pdf_file/0005/321971/Urban-green-spaces-and-healthreview-evidence.pdf?ua=1. Acesso em: 16 nov. 2018.

Recebido em 01/06/2019 - Aprovado em 25/07/2019. 